Revista Científica ANAP Brasil

ISSN 1984-3240 - Volume 13, número 29, 2020

\title{
Dinâmica Pluvial em Manaus e Ritmo Climático em Ano - Padrão
} Chuvoso

Rainfall Dynamics in Manaus and Climate Rhythm in Year - Rainy Pattern

Dinámica de la lluvia en Manaos y ritmo climático en el año - Patrón lluvioso

Jackeline Soares Andrade Mestranda em Geografia, UFAM, Brasil. soaresandradej@gmail.com

\section{Natacha Cíntia Regina Aleixo}

Professora Doutora, UFAM, Brasil. Natachaaleixo@yahoo.com.br

Leticia Braga de Oliveira Graduanda em Geografia, UFAM, Brasil. Leticiaoliveirab31@gmail.com 


\title{
Revista Científica ANAP Brasil
}

\author{
ISSN 1984-3240 - Volume 13, número 29, 2020
}

\section{RESUMO}

O estudo sobre o clima é de extrema importância para conhecimento dos fenômenos que atuam numa determinada região e subsidia o planejamento e a prevenção de riscos climáticos deflagrados no espaço urbano, como alagamentos e inundações. Dessa maneira, o objetivo deste trabalho foi analisar os anos padrão da precipitação pluvial e o ritmo climático em Manaus-AM. A análise desse trabalho partiu do referencial teórico e metodológico da climatologia geográfica, sendo que os dados de precipitação pluvial, foram coletados do INMET no período de 30 anos, tratados estatisticamente por técnicas descritivas e análise dos anos e meses-padrão das chuvas. Os resultados da análise rítmica dos meses mais chuvosos e secos, demonstraram quais foram os principais sistemas atmosféricos que atuaram e contribuíram para os acumulados diários e mensal das chuvas em Manaus.

PALAVRAS-CHAVE: Dinâmica Pluvial. Ritmo Climático. Manaus -AM.

\section{ABSTRACT}

The study of the climate is extremely important for the knowledge of the phenomena that operate in a given region and supports the planning and prevention of climatic risks triggered in the urban space, such as floods and floods. Thus, the objective of this work was to analyze the standard years of rainfall and the climatic rhythm in Manaus-AM. The analysis of this work was based on the theoretical and methodological framework of geographic climatology, and data on rainfall were collected from INMET over a period of 30 years, statistically treated by descriptive techniques and analysis of the years and standard months of rainfall. The results of the rhythmic analysis of the rainiest and driest months, showed which were the main atmospheric systems that acted and contributed to the daily and monthly accumulated rainfall in Manaus.

KEYWORDS: Rain Dynamics. Climate Rhythm. Manaus -AM.

\section{RESUMEN}

El estudio del clima es extremadamente importante para el conocimiento de los fenómenos que operan en una región determinada y apoya la planificación y prevención de los riesgos climáticos desencadenados en el espacio urbano, como las inundaciones y las inundaciones. Por lo tanto, el objetivo de este trabajo fue analizar los años estándar de Iluvia y el ritmo climático en Manaus-AM. El análisis de este trabajo se basó en el marco teórico y metodológico de la climatología geográfica, y los datos sobre las precipitaciones se obtuvieron del INMET durante un período de 30 años, tratados estadisticamente mediante técnicas descriptivas y análisis de los años y meses estándar de lluvia. Los resultados del análisis rítmico de los meses más lluviosos y más secos mostraron cuáles fueron los principales sistemas atmosféricos que actuaron y contribuyeron a la lluvia acumulada diaria y mensual en Manaus.

PALABRAS CLAVE: Dinamica de la lluvia. Ritmo climático Manaus -AM. 


\section{Revista Científica ANAP Brasil}

ISSN 1984-3240 - Volume 13, número 29, 2020

\section{INTRODUÇÃO}

A climatologia geográfica auxilia no entendimento dos elementos climáticos no cotidiano social. Os aspectos físicos do ambiente interagem de maneira diferenciada conforme o contexto geográfico e a produção do espaço.

A relação clima e ambiente está no cerne da discussão geográfica, pois, a Geografia trabalha o conceito de natureza de diferentes formas. Procedem destas concepções caminhos analíticos diferenciados: de um lado temos a natureza externa ao homem, conjunto de todas as coisas produzidas sem intencionalidade humana, portanto, algo distinto ao homem. De outro lado, temos um caminho analítico que entende a construção humana como natureza (MENDONÇA e KOZEL, 2002).

As anomalias climáticas têm sido discutidas há décadas, em especial as que enfocam o comportamento da precipitação pluvial e da temperatura. Além de estarem relacionadas ao fator natural da dinâmica atmosférica também se têm na escala regional e local a interferência da produção social e econômica do espaço, que influencia diretamente nas oscilações (ALEIXO, 2015).

Uma das temáticas de grande importância na atualidade tem sido a das mudanças e variabilidade climática, que vem ultrapassando as esferas acadêmicas e para ser discutida em contextos políticos e sociais diferenciados.

Os elementos climáticos podem ser analisados por meio de série temporal de dados que possibilitam a compreensão das derivações antrópicas ocasionadas pelas mudanças no uso do solo e condições socioambientais. A pluviosidade, por exemplo, relaciona-se com a disponibilidade hídrica e afeta o cotidiano populacional da população residente na região Amazônica, em contextos diferenciados como no transporte por navegação, na pesca, agricultura, abastecimento de água e energia hidroelétrica (ALEIXO, 2015).

Neste sentido, o estudo teve como objetivo analisar os anos padrão da precipitação pluvial e o ritmo climático em ano-padrão chuvoso em Manaus-AM. Uma vez que têm se a escassez de estudos sobre o comportamento do ritmo climático sob o olhar teórico e metodológico da climatologia geográfica.

O município de Manaus (figura 1) localiza-se na região Norte do Brasil e possui 1.802.014 habitantes o conforme o último Censo de 2010. Por localizar-se próxima à faixa equatorial, recebe durante todo ano alta quantidade de energia solar, que se reflete em temperaturas elevadas independentemente das estações do ano, com exceção dos dias com a presença de friagens (ALEIXO, 2015). 


\section{Revista Científica ANAP Brasil}

\section{ISSN 1984-3240 - Volume 13, número 29, 2020}

Figura 1: Mapa de localização do Município de Manaus - AM.

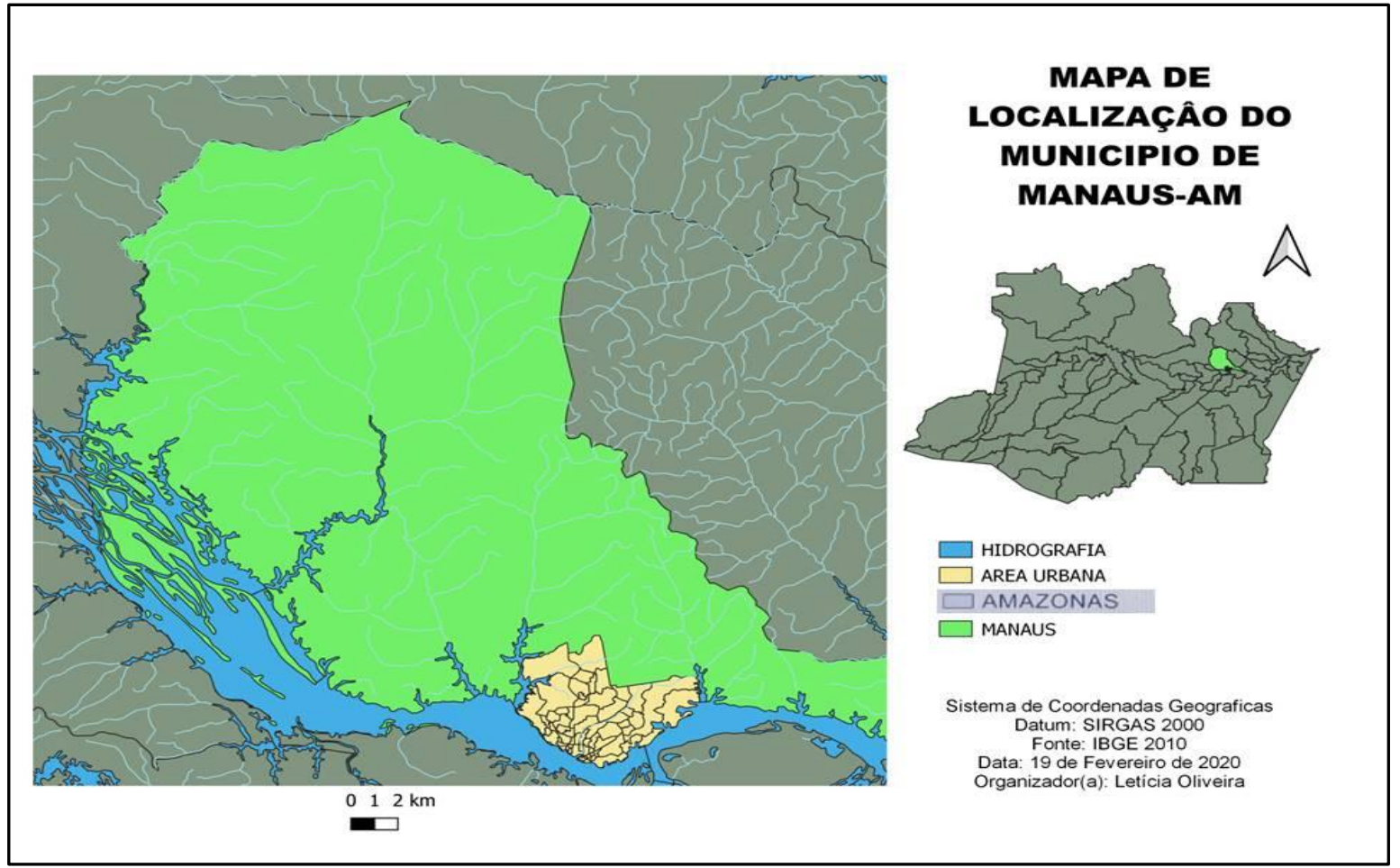

Fonte: IBGE. Org: Leticia Oliveira (2020)

\section{METODOLOGIA}

A análise partiu do referencial teórico e metodológico da climatologia geográfica proposto por Monteiro (1971), na qual é preciso considerar a gênese dinâmica da atmosfera relacionada à organização do espaço que afeta diretamente no balanço de energia gerando feedbacks complexos.

Foi utilizada a metodologia dos anos-padrão para a série dos últimos 30 anos analisados, proposta por Monteiro (1971) utilizada em diversos estudos de variabilidade climática no escopo da climatologia (SANT'ANNA NETO e ZAVATTINI, 2000).

Os anos-padrão foram analisados segundo os percentis definindo os valores de 0 a $15 \%$ para os anos secos, 15 a 35\% para anos tendentes a secos, 35 a $65 \%$ para anos habituais, 65 a $85 \%$ tendentes a chuvosos, e acima de $85 \%$ para anos chuvosos.

As classes foram definidas e representadas nos gráficos por cores: vermelha (ano seco) laranja (ano tendente a seco) cinza (ano habitual) azul claro (ano tendente a chuvoso) azul escuro (ano chuvoso).

Os dados de temperatura mínima, máxima e precipitação pluvial mensal e anual, foram coletados do posto meteorológico do Instituto Nacional de Meteorologia (INMET) no município de Manaus-AM. Esses dados foram tratados com técnicas estatísticas descritivas: média, amplitude, valor máximo e mínimo, percentil.

Foram elaborados gráficos no software Excel representando o regime das chuvas e da temperatura. 


\title{
Revista Científica ANAP Brasil
}

\author{
ISSN 1984-3240 - Volume 13, número 29, 2020
}

Também foram utilizadas imagens do satélite GOES 13 do CPTEC/INPE e o Boletim Climaanálise para avaliar a sucessão dos tipos de tempo atuantes em escala diária e análise do ritmo climático em meses representativos do período chuvoso e seco.

\section{RESULTADOS}

No trabalho foram utilizados dados 1986 a 2016 para verificar a variabilidade dos anos analisados, e desta forma identificar os anos padrão, em que foi observado nove anos considerados habituais, onze anos foram considerados tendente a seco e seco, e outros onze anos tendentes a chuvosos e chuvosos, conforme o (figura 2 ).

Figura 2: Gráfico dos Anos padrão de Manaus no período de 1986-2016.

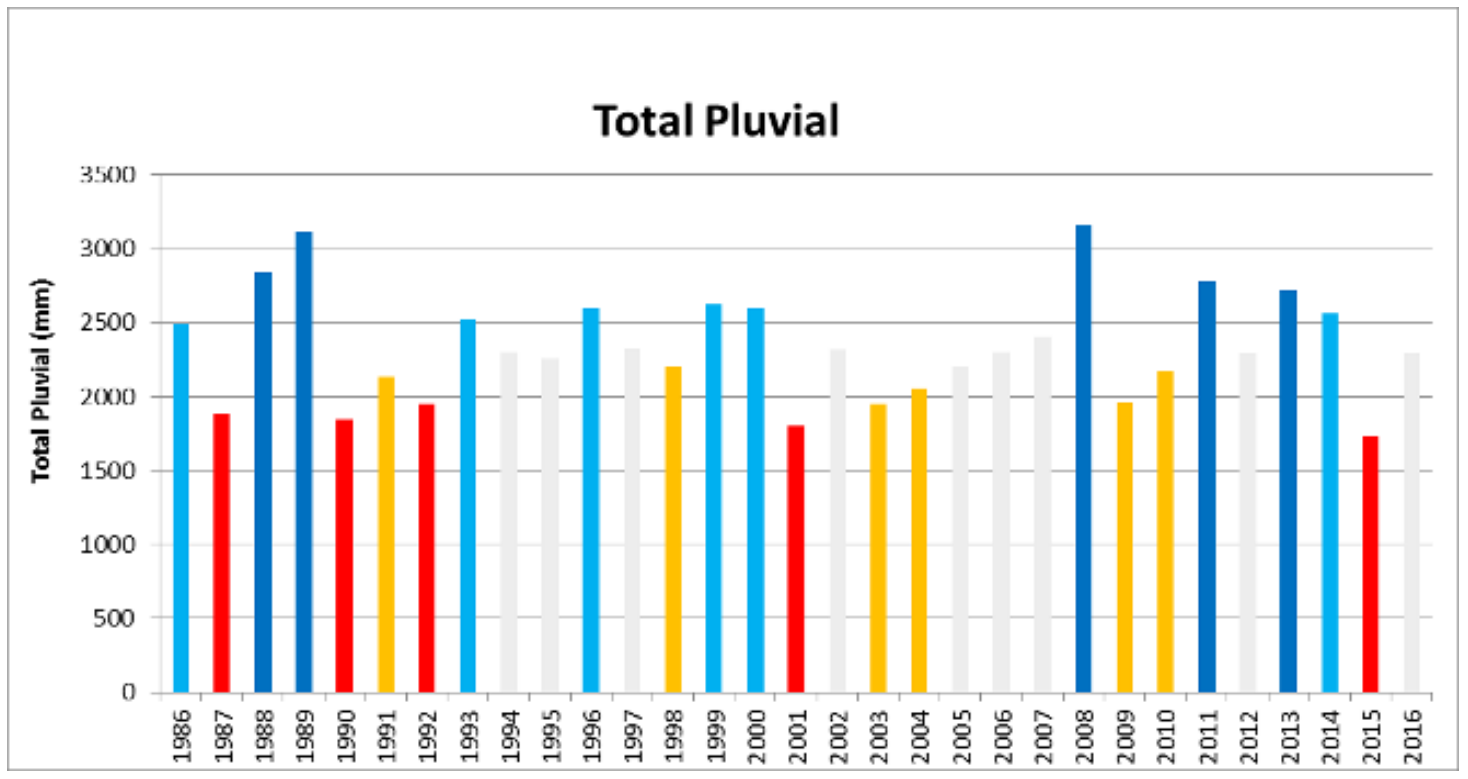

Fonte: INMET. Org: Jackeline Andrade, 2017

Em relação ao padrão de chuva mensal em Manaus (quadro 1), verificou-se que se inicia o período mais chuvoso a partir de dezembro e segue até maio onde predominam as maiores quantidades de meses tendentes a chuvosos e chuvosos. A partir de junho até o mês de outubro segue os meses que apresentam maior ocorrência de tendentes a secos e seco, o mês de novembro foi considerado um mês transicional.

O ano de 2008 foi considerado com padrão chuvoso e mostrou as seguintes características, nove (9) meses desse ano foram tendentes a chuvosos e chuvosos, três meses tendente a seco e dois meses habituais. 


\title{
Revista Científica ANAP Brasil
}

\author{
ISSN 1984-3240 - Volume 13, número 29, 2020
}

Quadro 1: Meses Padrão de chuva mensal em Manaus.

\begin{tabular}{|c|c|c|c|c|c|c|c|c|c|c|c|c|}
\hline & jan & fev & mar & $a b r$ & mai & jun & jul & ago & set & out & nov & dez \\
\hline 1986 & 267,1 & 294,9 & 304,4 & 279,5 & 203,6 & 102,8 & 183,9 & 1,6 & 71,1 & 214,6 & 321,8 & 246,9 \\
\hline 1987 & 291,5 & 289,1 & 277,6 & 291,2 & 167,8 & 28,2 & 20,7 & 76,8 & 64,6 & 46,3 & 128,3 & 195,2 \\
\hline 1988 & 269,7 & 546 & 265,6 & 254,7 & 297,7 & 229,1 & 82,3 & 35,6 & 110,6 & 111,5 & 226,9 & 412,1 \\
\hline 1989 & 292 & 417 & 252,2 & 370,8 & 555,1 & 184,5 & 157,5 & 15,8 & 136,4 & 185,6 & 326,4 & 220,1 \\
\hline 1990 & 234,3 & 190 & 299,2 & 236,4 & 244,6 & 89,3 & 114,1 & 72,3 & 22,8 & 56 & 116,9 & 167,3 \\
\hline 1991 & 278,5 & 223,8 & 309,2 & 342,9 & 322,2 & 137,9 & 173,9 & 55,4 & 39 & 79,4 & 37,9 & 137,9 \\
\hline 1992 & 236,5 & 262,7 & 347,8 & 218,6 & 118,8 & 61 & 90,3 & 100,3 & 90 & 87,4 & 71,2 & 265,6 \\
\hline 1993 & 436,5 & 617,4 & 229,3 & 370,3 & 96,8 & 61,5 & 34,6 & 47,7 & 21,9 & 99,8 & 256,3 & 251,3 \\
\hline 1994 & 371,1 & 399,5 & 259,5 & 258,7 & 174,2 & 125,2 & 33 & 96,7 & 62,6 & 91,8 & 207,3 & 222,5 \\
\hline 1995 & 286 & 132 & 301,4 & 480,5 & 217,5 & 107 & 76,9 & 34,2 & 72,4 & 81 & 312 & 160,5 \\
\hline 1996 & 571,3 & 257,6 & 338,1 & 428,5 & 127,5 & 185,1 & 16,9 & 65 & 114 & 186 & 163 & 142,2 \\
\hline 1997 & 220,6 & 344,5 & 534,9 & 310,8 & 252,2 & 9,5 & 0 & 111,5 & 40,5 & 60,9 & 182,3 & 261,5 \\
\hline 1998 & 302,6 & 171,7 & 210,8 & 407,2 & 273,4 & 167,2 & 92 & 41,8 & 115,6 & 73,5 & 153,6 & 191 \\
\hline 1999 & 411,6 & 260,8 & 233,2 & 421,2 & 445,4 & 149,3 & 25,3 & 40,6 & 98,8 & 132,3 & 203,5 & 198,3 \\
\hline 2000 & 350,2 & 344,4 & 340,7 & 535,4 & 172,6 & 48,2 & 40,8 & 140 & 218,1 & 47,2 & 169,7 & 192,3 \\
\hline 2001 & 348,4 & 219,5 & 216,8 & 188,2 & 231,6 & 164,1 & 30,6 & 14,9 & 88,2 & 28,1 & 55 & 213 \\
\hline 2002 & 380,8 & 239,9 & 195,3 & 376,7 & 262,9 & 159,1 & 3,4 & 35,4 & 60,1 & 216,1 & 81,2 & 311,2 \\
\hline 2003 & 105,8 & 340,9 & 209,2 & 390,1 & 219,6 & 110,7 & 93 & 118,3 & 60,9 & 96,9 & 119,6 & 89,9 \\
\hline 2004 & 179,6 & 150,6 & 424,2 & 227,2 & 422,9 & 120,2 & 59,6 & 141,3 & 112 & 66 & 13,3 & 140 \\
\hline 2005 & 165,7 & 331,5 & 334 & 404,8 & 225,5 & 53,5 & 52,4 & 16,2 & 45,9 & 75,2 & 211,6 & 291,8 \\
\hline 2006 & 173,3 & 346,4 & 265,3 & 252,1 & 382,1 & 87 & 71,6 & 16,7 & 32,8 & 66 & 294 & 317,4 \\
\hline 2007 & 414,4 & 137,7 & 336 & 343,1 & 165,3 & 100,2 & 121,9 & 133,3 & 71,7 & 28,5 & 226,2 & 327,9 \\
\hline 2008 & 397,4 & 298,8 & 553 & 345,4 & 264,1 & 202,7 & 80,2 & 58,4 & 56 & 162,2 & 280,8 & 458,1 \\
\hline 2009 & 310,8 & 457,9 & 232,5 & 222,1 & 114 & 165,8 & 25,1 & 5,4 & 4,2 & 26 & 132,3 & 262,4 \\
\hline 2010 & 295,8 & 352,5 & 206,4 & 303,4 & 165,1 & 119,1 & 100,6 & 54,8 & 26,6 & 116,9 & 140,6 & 290,1 \\
\hline 2011 & 226,8 & 493,3 & 323,3 & 515,9 & 222,4 & 121,3 & 20,2 & 64,3 & 41,5 & 283,7 & 272,8 & 194,5 \\
\hline 2012 & 365,2 & 288,7 & 277,4 & 195,6 & 167,8 & 85,4 & 83 & 26,6 & 90,3 & 181,3 & 284,5 & 248,6 \\
\hline 2013 & 314,6 & 342,1 & 427,4 & 420,6 & 238,4 & 32,3 & 167,1 & 53,0 & 121,0 & 193,0 & 312,2 & 101,3 \\
\hline 2014 & 253,3 & 245,4 & 527,7 & 255,0 & 411,3 & 211,7 & 66,1 & 32,2 & 0,0 & 190,9 & 196,0 & 173,8 \\
\hline 2015 & 303,7 & 214,0 & 373,7 & 165,5 & 280,8 & 75,8 & 47,3 & 10,7 & 15,8 & 31,3 & 90,7 & 126,4 \\
\hline 2016 & 129,6 & 235,3 & 281,9 & 303,9 & 117,5 & 97,1 & 103,2 & 49,8 & 112,0 & 152,2 & 193,7 & 518,8 \\
\hline
\end{tabular}

Fonte: INMET. Org: Jackeline Andrade, 2017.

\subsection{Ritmo Climático do Ano de 2008 - Ano Padrão Chuvoso}

O ano padrão de 2008 obteve o total pluvial anual de 3157,1 mm com 196 dias de precipitação durante o ano, desta forma foi escolhido para a realização da análise rítmica. Os meses que tiveram os dois maiores e os dois menores totais de precipitação deste ano foram analisados neste trabalho para demostrar os principais sistemas atmosféricos integrados aos elementos do clima em Manaus.

Nesse ano-padrão as chuvas mensais distribuíram-se da seguinte forma janeiro, fevereiro, março, abril, maio e dezembro como meses considerados chuvosos e junho, julho, agosto, setembro, outubro e novembro como meses considerados secos. Isso tem forte relação com o fenômeno La Niña, pois, o mesmo ano se encontra totalmente inserido no período do acontecimento do fenômeno e podemos verificar também quais foram os sistemas atmosféricos que atuaram neste ano de La Niña em Manaus caracterizado como o mais chuvoso da série histórica de 30 anos analisada.

A partir do (quadro 1) dos meses padrão, no ano de 2008 podemos verificar que o mês de Março teve o maior índice de precipitação com total de $553 \mathrm{~mm}$, seguido de dezembro com 458,1 mm destacando-se perante os outros meses como os dois mais chuvosos. Já o mês de setembro foi 


\section{Revista Científica ANAP Brasil}

\section{ISSN 1984-3240 - Volume 13, número 29, 2020}

considerado o mais seco com índice de precipitação mensal menor que $56 \mathrm{~mm}$, acompanhado do mês de julho com $58,4 \mathrm{~mm}$.

Desta formar no gráfico de análise rítmica do mês de Março (figura 3), com maior total mensal de precipitação pluvial distribuídos em 24 dias de ocorrência, verificou-se que no dia 15 a precipitação foi maior que 70 milímetros e no dia 11 foi maior que 60 milímetros e os outros dias foram abaixo desse nível.

Figura 3: Gráfico de análise rítmica de Março de 2008.

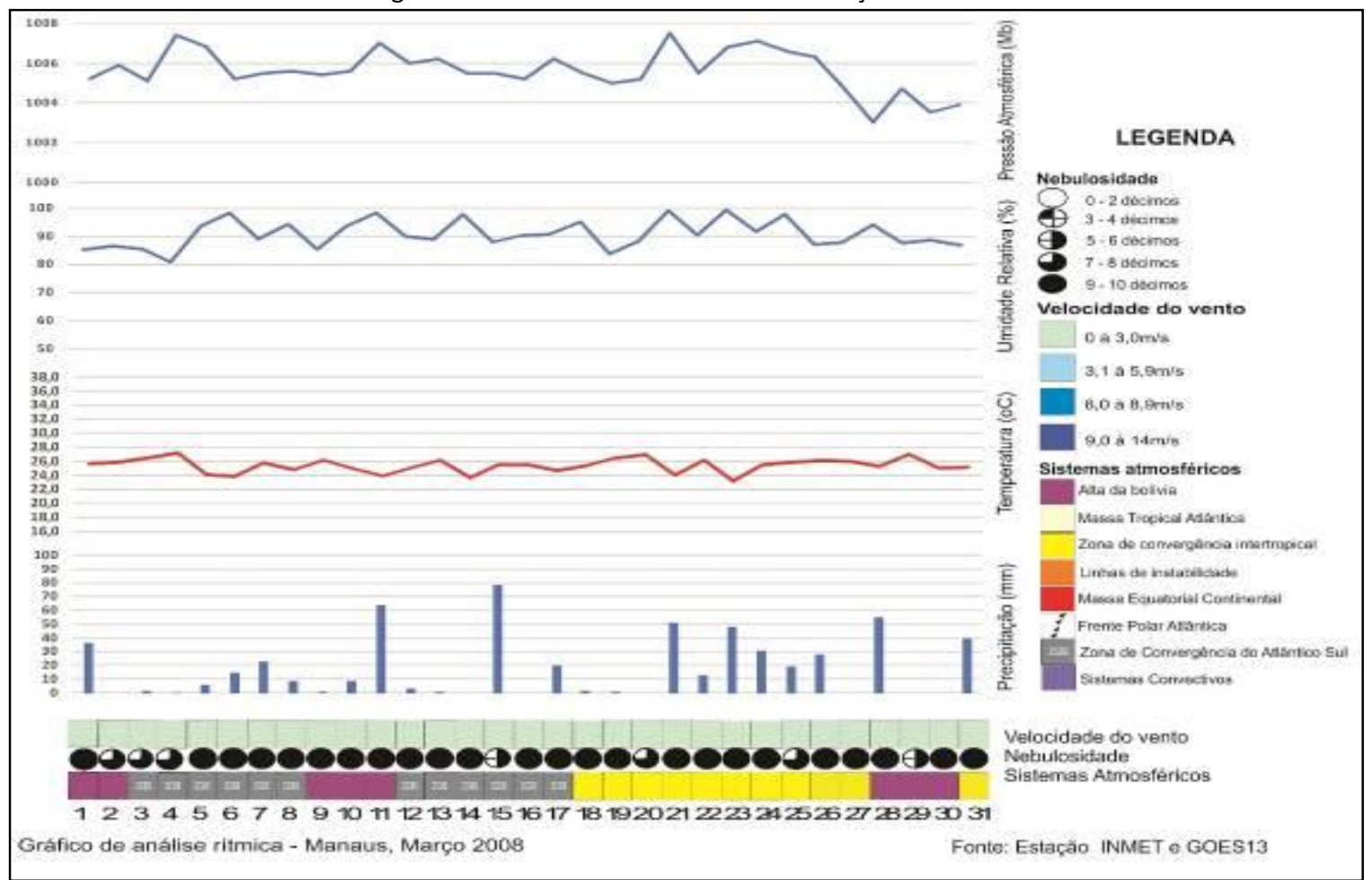

Fonte: INMET e satélite GOES 13. Org: Jackeline Andrade, 2017.

Os principais sistemas que atuaram nesse mês foram: a ZCAS (Zona de Convergência do Atlântico Sul) o primeiro episódio ocorreu entre os dias 3 e 8, o segundo episódio entre os dias 12 e 17 de março totalizando 12 de ocorrências de ZCAS. A Zona de Convergência Intertropical (ZCIT), atuou 11 dias do mês entre os dias 18 e 27 e no dia 31, o sistema alta da Bolívia ocorreu durante 8 dias do mês.

Em relação a temperatura deste mês, a mínima ficou em $22,8^{\circ} \mathrm{C}$ e máxima de $31,1^{\circ} \mathrm{C}$, com amplitude de $8,3^{\circ} \mathrm{C}$. A média total da umidade relativa ficou em $90,6 \%$, com velocidade do vento baixa entre 0 a $3,0 \mathrm{~m} / \mathrm{s}$ durante os dias do mês.

O mês de dezembro foi considerado o segundo maior em índice de precipitação no ano de 2008 com 458,1 mm (figura 4), o sistema atmosférico ZCAS tendo uma maior predominância ocorrendo três episódios no mês. 0 primeiro episódio começou no dia 3 ao dia 7, o segundo no dia 12 até o dia 20 e o terceiro do dia 25 ao dia 28 de dezembro. O sistema Alta da Bolívia predominou durante 8 dias, ZCIT (zona de convergência intertropical) atuou durante 5 dias do mês. Nesse mês, 22 dias foram nublados e 9 dias foram parcialmente nublados. 


\title{
Revista Científica ANAP Brasil
}

\author{
ISSN 1984-3240 - Volume 13, número 29, 2020
}

Com a influência desses sistemas, 20 dias do mês tiveram precipitação pluvial e alguns dias com índices elevados, como no dia 27 a precipitação foi maior que $70 \mathrm{~mm}$ e nos dias 22 e 31 a precipitação foi maior que $50 \mathrm{~mm}$, no dia 2 a precipitação foi maior que 40 milímetros e os outros dias chuvosos tiveram totais abaixo desse nível. A temperatura mínima ficou em média $23,5^{\circ} \mathrm{C}$ e a máxima $31,9^{\circ} \mathrm{C}$, com amplitude de $8,4^{\circ} \mathrm{C}$, a média total da umidade relativa ficou em $86,8 \%$, com velocidade do vento entre 0 à $3,0 \mathrm{~m} / \mathrm{s}$.

Figura 4: Gráfico de análise rítmica de Dezembro de 2008.

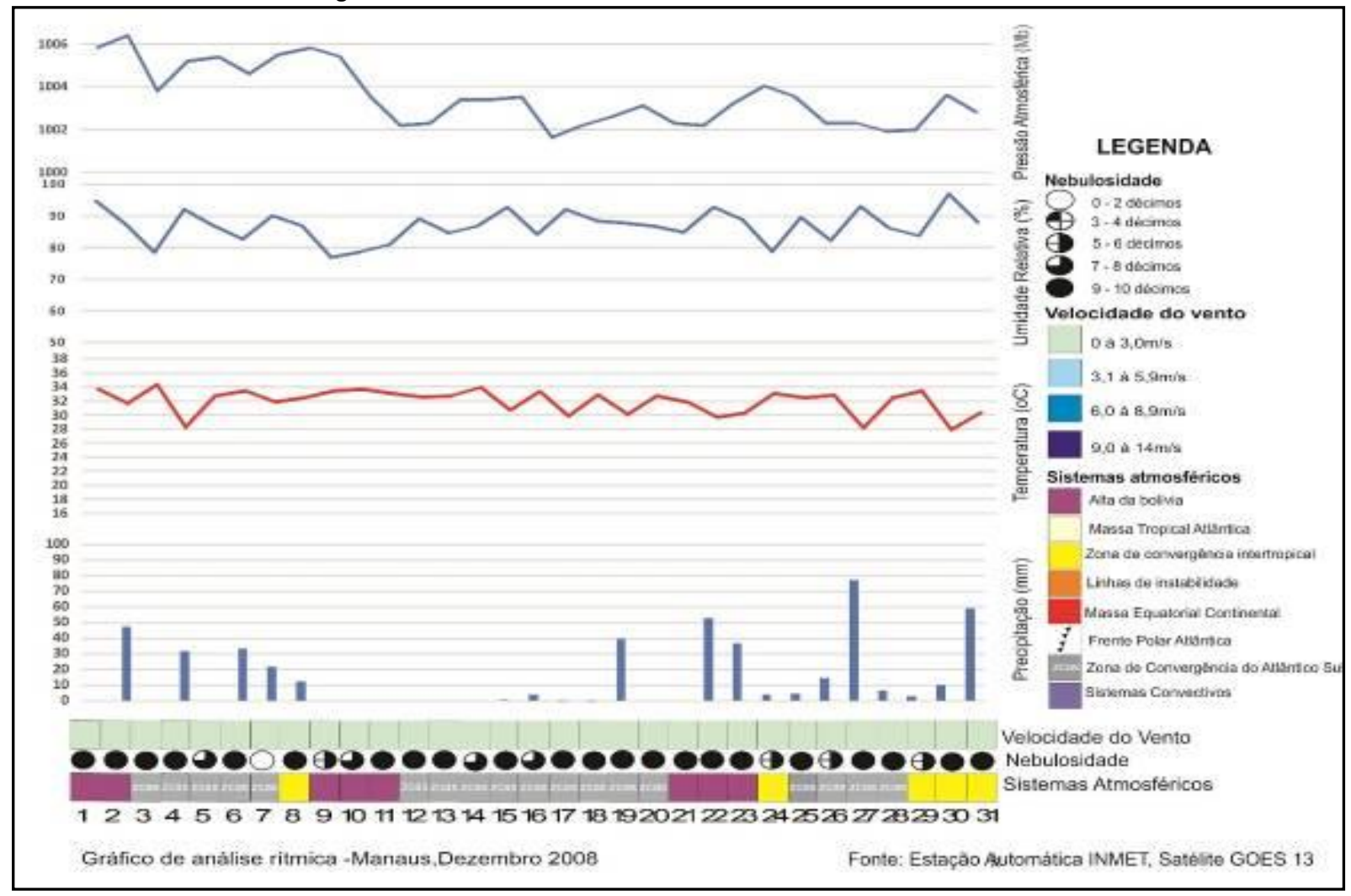

Fonte: INMET e satélite GOES 13. Org: Jackeline Andrade, 2017.

O mês de setembro (figura 5), que foi considerado com o menor índice de precipitação pluvial com um total de $56 \mathrm{~mm}$, apresentou apenas 11 dias do mês com chuvas.

No dia 13 de setembro a precipitação foi maior que $10 \mathrm{~mm}$ e os outros dias chuvosos ficaram abaixo desse nível, desta forma, caracterizado como um outro mês seco igual a julho e agosto, com poucos dias de precipitação.

O sistema atmosférico que teve grande predominância foram os convectivos com 18 dias de ocorrência. Sendo nesse mês 12 dias totalmente nublados e outros 14 dias foram parcialmente nublados e 5 dias considerados dias limpos sem nebulosidade.

A massa equatorial continental predominou 9 dias, sendo que foi considerada para o tipo de tempo com presença de nuvens e com formação de sistema convectivo e alta temperatura, condições típicas da região amazônica. No mesmo mês, 3 dias foram influenciados pelas linhas de instabilidade. A temperatura mínima ficou em $23,9^{\circ} \mathrm{C}$ e máxima de $34,4^{\circ} \mathrm{C}$, com amplitude de $10,5^{\circ} \mathrm{C}$, a média total da umidade relativa ficou em $82,3 \%$ e a média da pressão atmosférica ficou em 1005,3 mb, e com velocidade do vento entre 0 à $3,0 \mathrm{~m} / \mathrm{s}$. 


\section{Revista Científica ANAP Brasil}

\section{ISSN 1984-3240 - Volume 13, número 29, 2020}

Figura 5: Gráfico de análise rítmica de setembro de 2008.

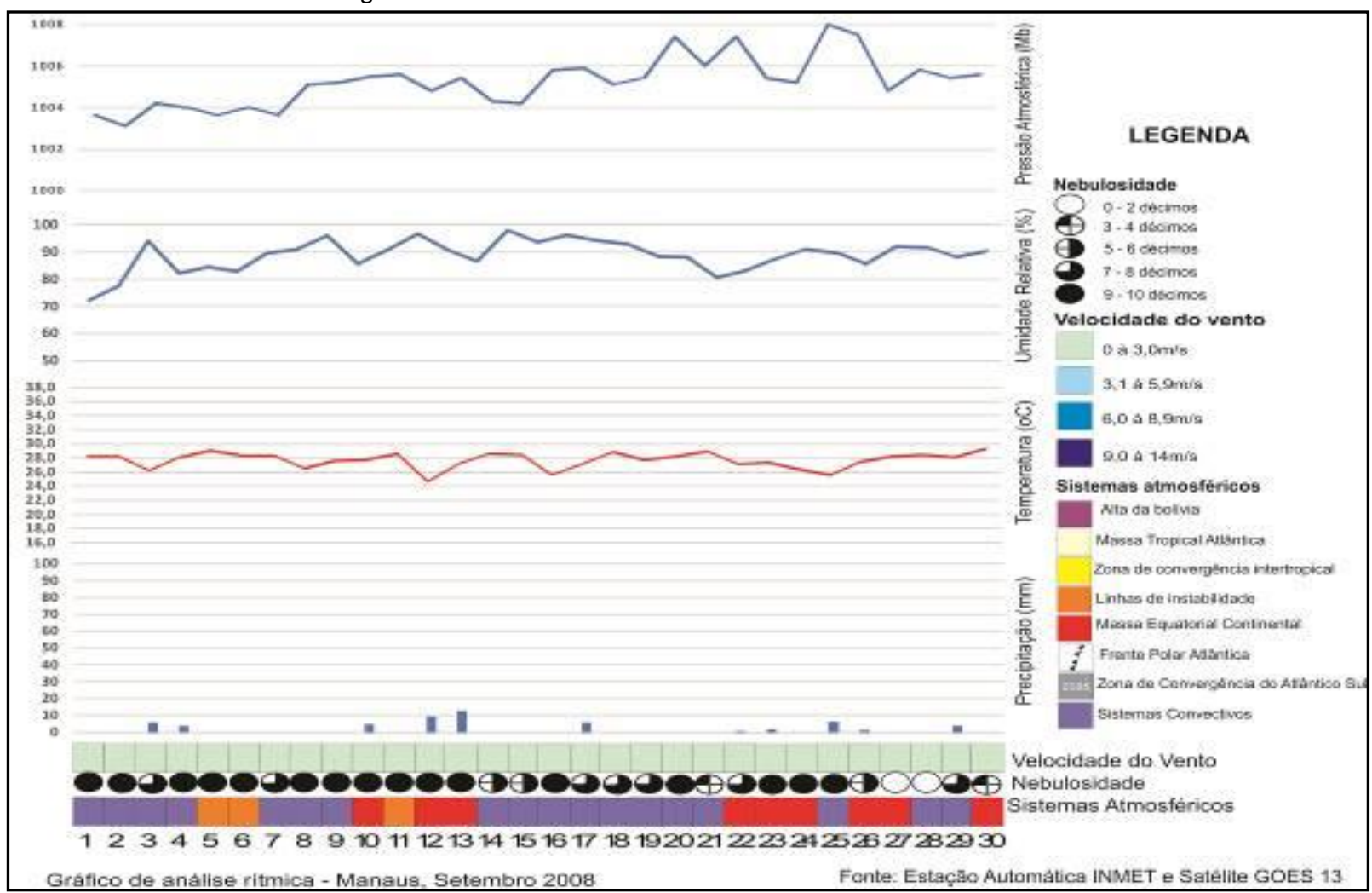

Fonte: INMET e satélite GOES 13. Org: Jackeline Andrade, 2017.

O mês de julho foi o segundo mês com o menor índice de precipitação pluvial e considerado seco (figura 6), o sistema atmosférico que teve grande predominância no mês foi a massa equatorial continental com 22 dias e outros 8 dias do mês tiveram a presença dos sistemas convectivos. Sendo nesse mês, 15 dias foram nublados e outros 15 dias foram parcialmente nublados.

Com a influência desses sistemas o mês teve apenas 6 dias de precipitação, os acumulados de chuvas foram abaixo do nível para maior parte da região norte nesse mês, sendo que no dia 25 a precipitação em Manaus foi maior que 30 milímetros e no dia 11 foi maior que 20 milímetros, e os outros dias foram abaixo desse nível, com isso, considerado um mês seco. A temperatura mínima ficou em $23,5^{\circ} \mathrm{C}$ e máxima de $33,6^{\circ} \mathrm{C}$, com amplitude de $10,1^{\circ} \mathrm{C}$. A média total da umidade relativa ficou em $85,9 \%$ com velocidade do vento entre 0 e $3,0 \mathrm{~m} / \mathrm{s}$. 
Figura 6: Gráfico de análise rítmica de Julho de 2008.

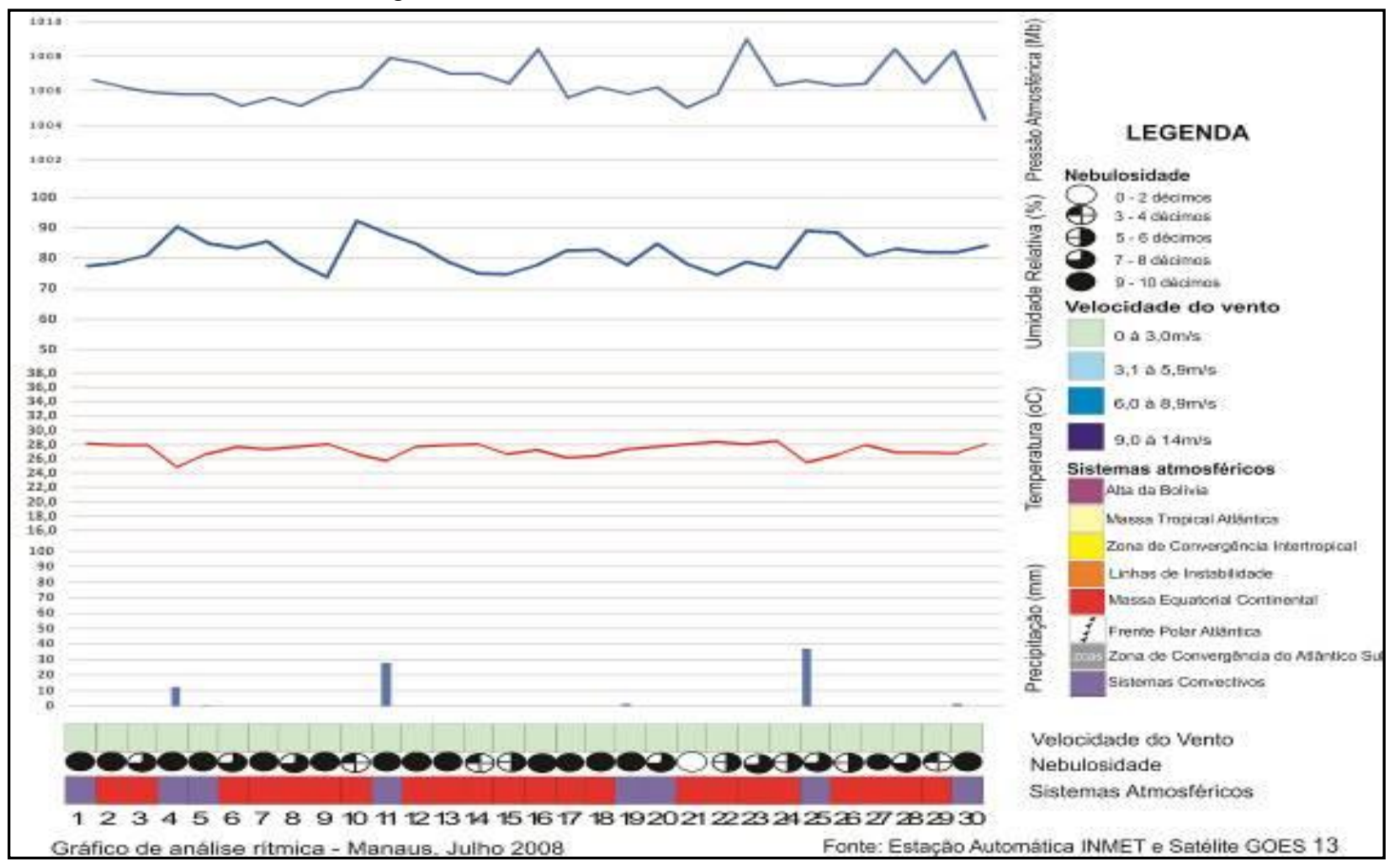

Fonte: INMET e satélite GOES 13. Org: Jackeline Andrade, 2017.

\section{CONSIDERAÇÕES FINAIS}

Na pesquisa verificamos que os principais sistemas atmosféricos que atuaram nos meses de janeiro, fevereiro, março, abril, maio e dezembro que são considerados os meses chuvosos, foram a ZCIT, ZCAS e Alta da Bolívia e junho, julho, agosto, setembro, outubro e novembro meses considerados secos, com predomínio da Massa Equatorial Continental, Sistemas Convectivos e Linhas de Instabilidade.

A partir dos gráficos de análise rítmica, podemos verificar os dois meses com maiores índices de precipitação que foram março e dezembro, também os meses com os menos índices como o mês de setembro e julho, destacando quais foram os principais sistemas atmosféricos que atuaram nesses meses que contribuíram com os acumulados de chuvas em Manaus. Ressaltase que foram associados os sistemas atmosféricos e a massa equatorial continental (como condição habitual na região amazônica central) que potencializa e influência na formação de outros sistemas de mesoescala e grande escala associados, porém, nem sempre bem definidos. Esses resultados obtidos nesta pesquisa nos mostram a contribuição da análise dos anos-padrão e ritmo climático para compreendermos melhor o clima em contexto amazônico e subsidiar políticas de planejamento integradas a relação sociedade e natureza, podendo também a partir dos achados relacionar o presente estudo a outros temas da climatologia como saúde, agricultura, excepcionalidades, desta forma, também contribuindo para o avanço das pesquisas na área de climatologia geográfica e geografia do clima no Amazonas. 


\title{
Revista Científica ANAP Brasil
}

\author{
ISSN 1984-3240 - Volume 13, número 29, 2020
}

\section{AGRADECIMENTOS}

Ao Instituto Nacional de Meteorologia por disponibilizar os dados utilizados neste trabalho e ao laboratório de Hidrogeografia e Climatologia da Amazônia - HIDROGEO, da Universidade Federal do Amazonas.

\section{REFERÊNCIAS BIBLIOGRÁFICAS}

ALEIXO, N.C.R.; SILVA NETO, J. C. A. Variabilidade Climática e transformação da paisagem no município de Tefé-AM In: Fórum ambiental: uma visão multidisciplinar da questão ambiental. 2 ed. Tupã: ANAP, 2015, v.1, p. 225-241.

MENDONÇA, F., KOZEL, S. Elementos de epistemologia da Geografia Contemporânea. Curitiba, Ed. da UFPR, 2002. SANT'ANNA NETO, J. L. As chuvas no Estado de São Paulo: contribuição ao estudo da variabilidade e tendência da pluviosidade na perspectiva da análise geográfica. Tese (Doutorado). Programa de Pós-Graduação em Geografia Física. São Paulo: USP, 1995.

SANT’ANNA NETO, J.L.; ZAVATINI, J.A. Variabilidade e Mudanças Climáticas. Maringá: EDUEM, 2000. 